\title{
CryoSat \\ - braste forventninger
}

Af Rasmus T. Tonboe DMI, Leif Toudal Pedersen DTU, Søren Andersen DMI og Rashpal S. Gill DMI

I løbet af de seneste 30 år er både tykkelsen af den arktiske havis og udbredelsen, specielt om sommeren, mindsket. Gennemsnittet af den årlige udbredelse er mindsket med $8 \%$ svarende til et areal på størrelse med Skandinavien (Danmark, Norge, Sverige og Finland), mens sommerudbredelsen er reduceret med 15-20 \%. I 2005 målte man den mindste sommerudbredelse af den Arktiske havis nogensinde. Tykkelsen er reduceret med mindst 10-15\%.

Reduktionen i udbredelsen af havis, der reflekterer solens stråling, gør, at absorption af strålingen om sommeren bliver større, og dermed øges opvarmningen yderligere i en selvforstærkende proces. Denne proces sammen med det reducerede snedække på land er medvirkende til, at temperaturstigningen i Arktis er ca. 2 gange større end det globale gennemsnit. Faktisk skyldes ca. $20 \%$ af den globale temperaturstigning re-

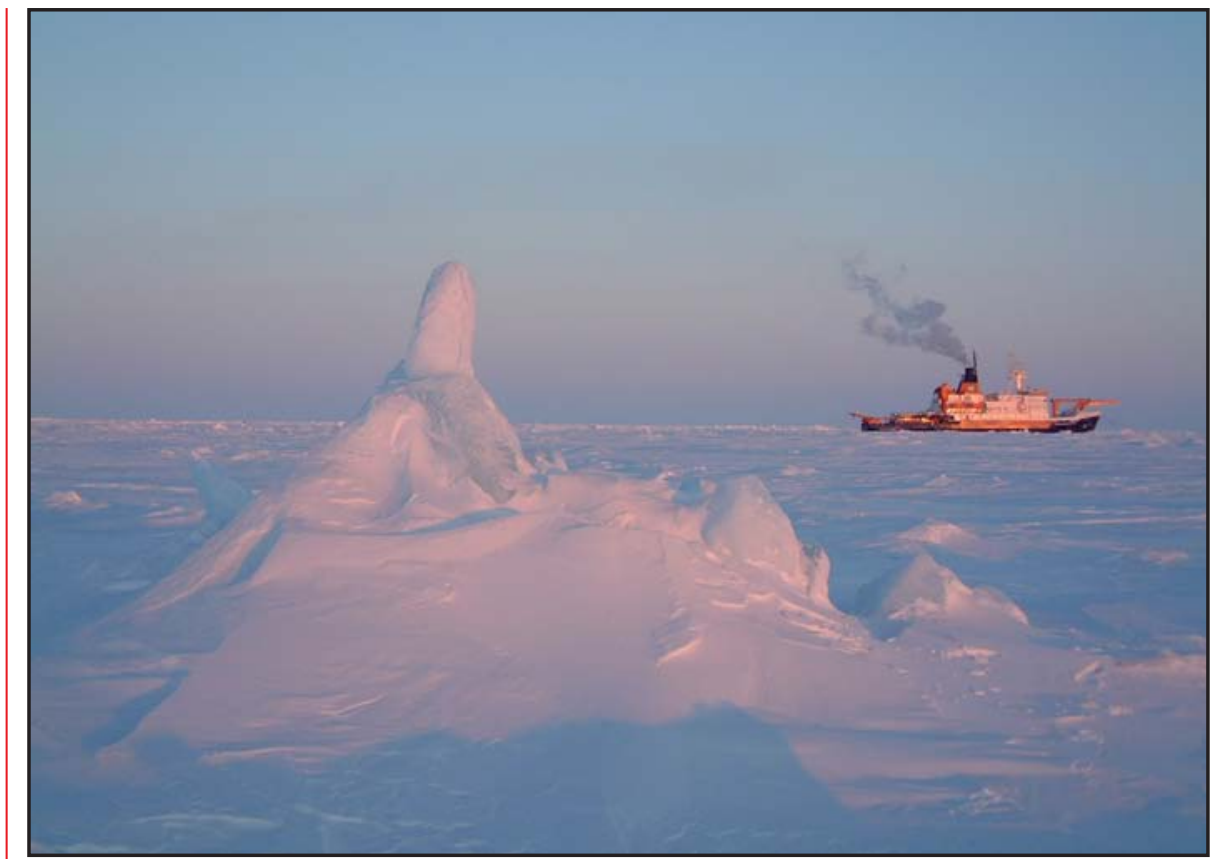

Den tyske isbryder Polarstern i havisen 2003. (Foto: Martin Doble)

duktioner i snedække og havisens udbredelse.

Modelberegninger viser, at $2 / 3$ af havistykkelsesreduktionen er termodynamisk (varmere atmosfære og hav), og resten skyl- des ændringer i cirkulationsmønstret. På grund af den reducerede afkøling og saltholdigheden af overfladevandet i Grønlandshavet frygtes ændringerne også at have konsekvenser for den termohaline havcirkulation

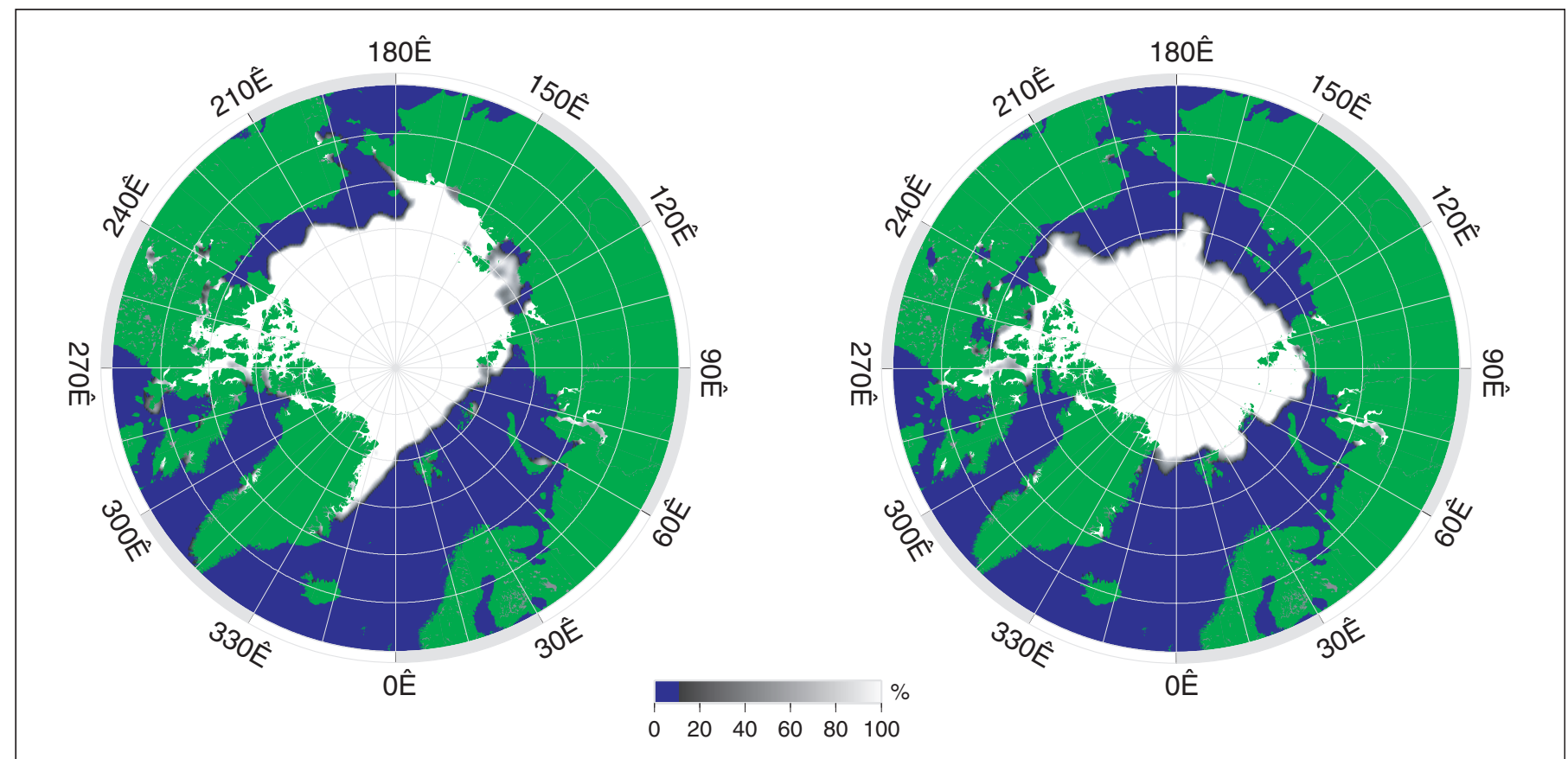

Den arktiske havisudbredelse i september 1979 og 2002 målt med satellitbårne mikrobølge radiometre. Isudbredelsen er på det årlige minimum i september. (Grafik: Forfatterne) 
fx den nordatlantiske strøm, som gør klimaet $5-10^{\circ} \mathrm{C}$ varmere i Nordvesteuropa end gennemsnittet på disse breddegrader. Denne bekymrende udvikling i og omkring det Arktiske havisdække var motivationen for udviklingen af ESA's første satellit i Living Planet-programmet, nemlig CryoSat, med det formål at måle havistykkelse og kortlægge verdens gletschere og iskapper. Desværre ramte CryoSat havisen nord for Grønland kun minutter efter opsendelsen d. 8. oktober 2005 på grund af en fejl i et raketmodul.

\section{Hvorfor opsende satellitten?}

Ud over støtte til europceisk industri, hvorfor ønsker man da at sende en 525 mio. $k r$. dyr satellit i omløb for at måle pa Jordens is? Der er et stærkt samspil mellem havis og klima, og hvis man er i stand til at kortlægge dette samspil, kan man sige noget mere generelt om klimaet ved at kigge på havisen. Klimaprocesser omkring havis er dårligt eller kun delvist kortlagt, fx er havistykkelsen en af de centrale parametre, som ikke kortlægges systematisk, og den er derfor behæftet med stor usikkerhed.

Den utilstrækkelige kortlægning er medvirkende til, at modelberegninger af fremtidens klima også er behæftet med stor usikkerhed. Pålidelige målinger og dermed modelberegninger, som CryoSat skulle have bidraget med, er afgørende for klimadebatten og beslutningsprocessen i klimarelaterede spørgsmål.

\section{Radaraltimetre til måling af havoverflade} Hvordan skulle CryoSat have målt isen? Normalt bruges satellitbårne radaraltimetre til at måle den isfri havoverfladehøjde, og disse data er i dag helt uundværlige til assimilering i oceanmodeller, etablering af geoiden og studier af El Niño. I løbet af de seneste få år er man blevet i stand til at reprocessere altimeterrådata over havis for at bestemme hav/isoverfladens højde. Desværre dækker ESA's seneste altimetre kun op til 81, $5^{\circ}$ svarende til Nordøstrundingen i Grønland og altså ikke størstedelen af det Arktiske Ocean. Dette hul skulle dækkes af Cryosat.

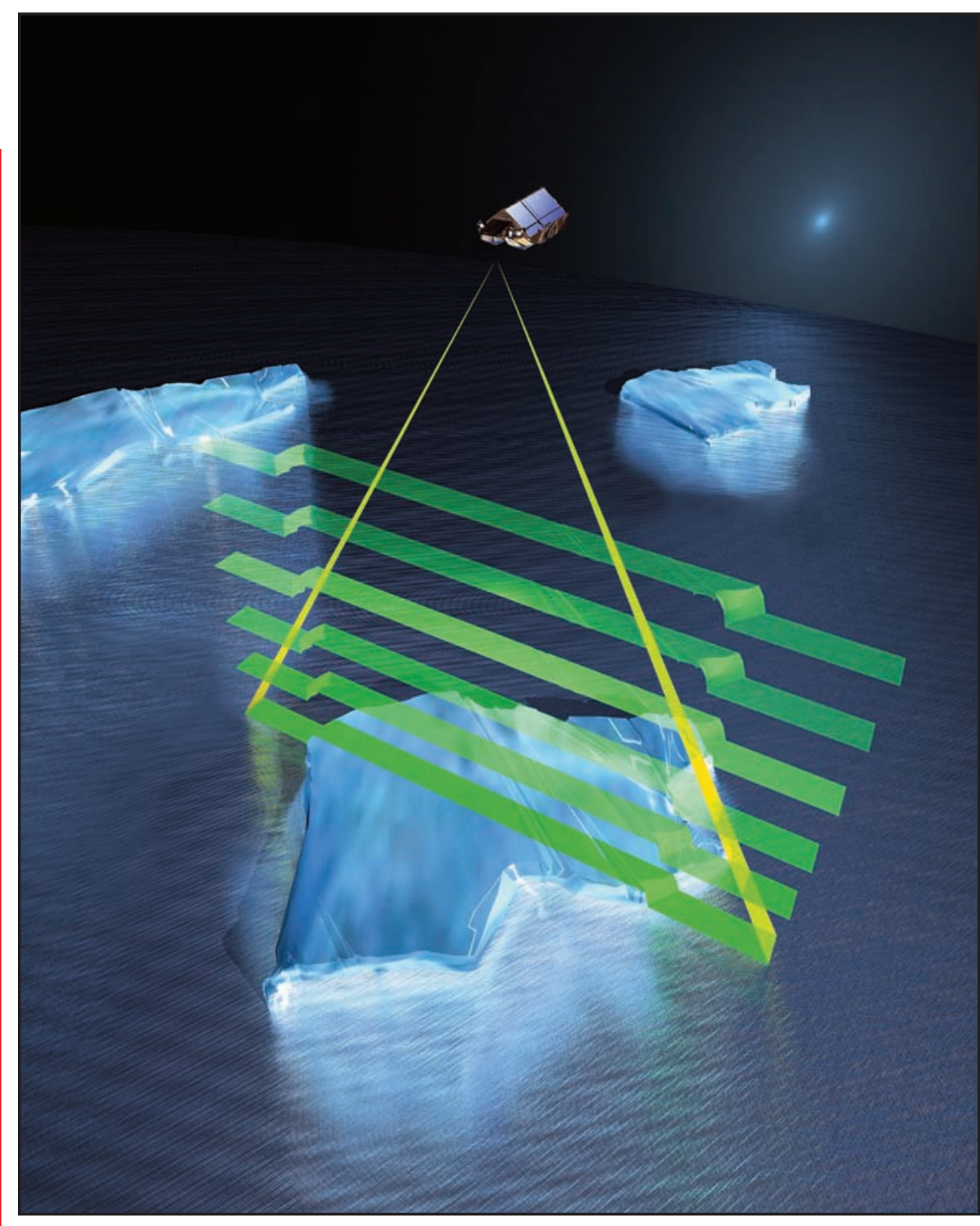

Sådan ville CryoSats operation have set ud i SAR mode over havis. (Grafik: ESA)

\section{Måling af isoverflade højden}

Teknisk set kunne CryoSat imødekomme de problemer, der er ved at anvende radaraltimeter til at bestemme havistykkelse. Tykkelsen af havisen kan bestemmes ved at måle forskellen imellem havisens frihøjde og vandoverflade højden i sprækker og åbent vands områder i nærheden. Her er radarens rumlige opløsning og målefrekvens væsentlige begrænsninger for at få "rene" målinger fra is og vand. Desuden kræves en altimetersatellit med stejl inklination for at dække det Arktiske Ocean eller Sydpolens iskappe.

\section{Radarudbredelsen}

Lokalisering af satellittens bane er en af de afgørende årsager til at måle nøjagtigheden, som over åbent hav er væsentligt bedre for nutidige altimetre $(\mathrm{ca} .2 \mathrm{~cm}$ ) end med det første satellitbårne altimeter Seasat i 1978 (ca. $25 \mathrm{~cm}$ ). Ud over nøjagtig banebestemmelse korrigeres desuden for refraktion $\mathrm{i}$ atmosfæren dvs. sænkning af mikrobølge- 

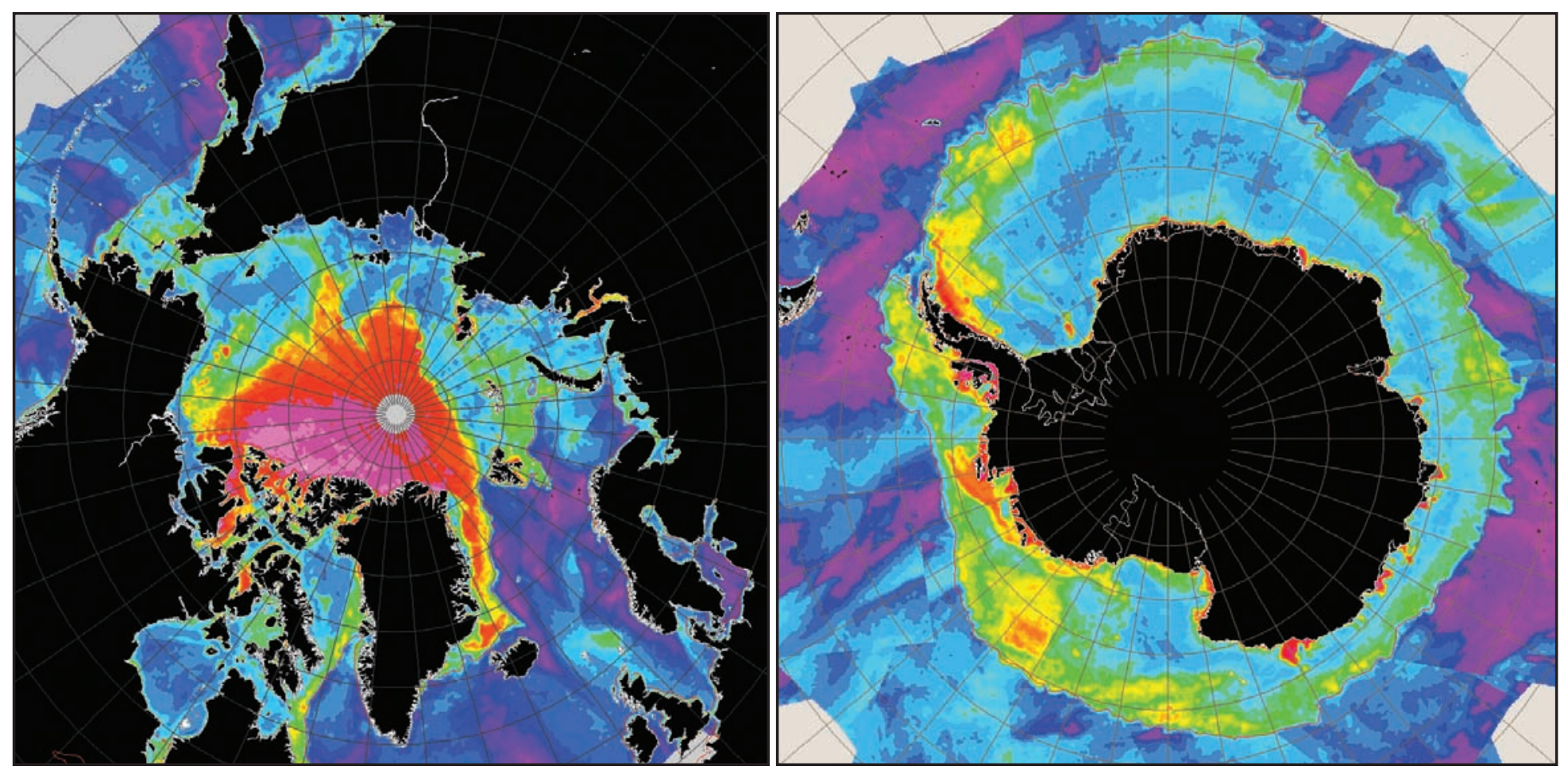

Kort over tilbagespredningskoefficienten fra den amerikanske radarsatellit QuikScat ved maksimal isudbredelse i Arktis i marts og Antarktis i september, 2005. Den sorte konturline viser iskoncentrationer på $30 \%$, hvilket omtrent er sammenfaldende med iskanten. QuikScats radar-scatterometer opererer ved samme bølgelængde som CryoSat, men i modscetning til altimeteret kigger den til siden ca. $50^{\circ}$. Dette har stor betydning for tilbagespredningsmekanismerne. Hvor altimeter-tilbagespredningskoefficienten fra is domineres af glatte og flade områder, er scatterometret påvirket af ru og porøse overflader og områder med grove snekorn. Tilbagespredningskoefficienten fra disse to instrumenter er ncesten komplementcr. Se flere aktuelle og historiske satellit-billeder af havis på www.seaice.dk.(Grafik: Forfatterne)

udbredelseshastigheden som funktion af tryk, temperatur, vanddamp, skyvand i troposfæren og tætheden af frie elektroner i ionosfæren.

Modsat salt havvand gennemtrænger radaren til dels sne og is. Tilbagespredningen starter ved sneoverfladen, men interne islag $i$ sneen og for havis også isoverfladen bidrager tillige til signalet. Den effektive spredningsdybde afhænger derfor af sneens lagdeling, dielektriske egenskaber og tykkelse.

Radarens gennemtrængning $i$ is og sne udgør en væsentlig usikkerhed. En usikkerhed der er vanskelig at kvantificere og korrigere, fordi egenskaber af sneen oven på havisen ikke kortlægges systematisk og globalt. Teoretiske beregninger viser, at indtrængningen sammen med isflagens ligevægtsfrihøjde potentielt gør det vanskeligt at bestemme havistykkelsen, med mindre man fx kender snetykkelsen. Det er derfor ikke givet, at måling af havistykkelse med CryoSat ville være blevet en ubetinget succes medmindre, der blev gjort væsentlige fremskridt inden for satellitkortlægningen af for eksempel sne.

\section{Havisparametre}

Netop kortlægningen af sne på havis er et eksempel på en anden vigtig klimaparameter, der i dag kun kortlægges ufuldstændigt. Et andet problem er kortlægningen af åbent vands sprækker i det næsten $100 \%$ isdækkede Arktiske Ocean. Undersøgelser viser, at numeriske atmosfæremodeller, $\mathrm{fx}$ dem man bruger til at beregne vejrudsigter $\mathrm{i}$
Danmark, giver bedre resultater, hvis man bruger et konstant mål for andelen af åbent vands sprækker, i stedet for det man i dag kan måle med satellit. Derudover er der istype, isdrift, havisskruninger, albedo/ emissivitet, tykkelsesfordeling, temperatur, aerodynamisk ruhed osv.

Der er således mange andre vigtige havisparametre end istykkelse, og der er et behov for at kortlægge flere af disse bedre og mere systematisk. I løbet af de næste år opsendes flere nye satellitter, som forhåbentlig vil bidrage til at kortlægge samspillet mellem havis og klima og reducere usikkerheden i fremtidens klimaprognoser.

Metoder til kortlægning af havistykkelse Når man nu ikke har CryoSat - hvad gør man så? I dag bruges to metoder til at måle tykkelsen:

Borehuller: Metoden er teknologisk ukompliceret og giver et præcist estimat, men det er hårdt arbejde at bore et repræsentativt antal huller for et givent område. Metoden er urealistisk på global skala.

Upward Looking Sonar (ULS): Akustisk instrument monteret enten på ubåd eller på havbunden under en strøm af drivende is (Fram Strædet). Ubåds-ULSmålinger fra 1960'erne til i dag udgør det væsentligste havistykkelsesdatasæt og bruges som reference for den observerede udtynding. Metoden underrepræsenterer tyndis, og man antager en effektiv ismassefylde (sne + is) for at beregne den absolutte tykkelse. Desuden er dækningen sporadisk.

\section{Eksperimentelle metoder}

Der eksisterer flere eksperimentelle metoder til bestemmelse af havistykkelse herunder altimetri. Måling af isens frihøjde for at bestemme istykkelsen med altimeter har været omgæret med skepsis, fordi både frihøjde og usikkerhed bliver ganget med ca. 10 for at udlede tykkelsen (man kan kun måle den del af isen, der rager op over vandet, resten må man regne sig til ved antagelser om isens massefylde og snedække). Det er desuden afgørende, at man har et ikke-klimatologisk mål for snedækket.

Laseraltimetre fra fly er afprøvet og an-

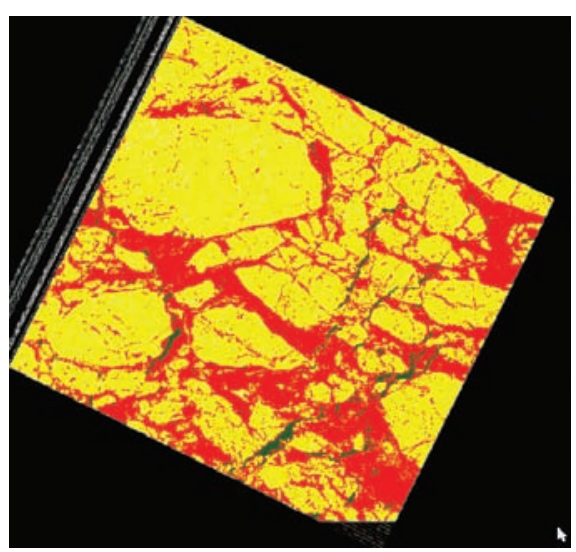

Radarsat SAR dataklassifikation af istyper (100 x $100 \mathrm{~km}$ ) i Fram Strcedet. Klassifikationen viser polaris (gul), vinteris (rød) og åbent vands sprcekker (mørkegrøn). Disse typer har forskellig tykkelse. (Grafik: Forfatterne) 


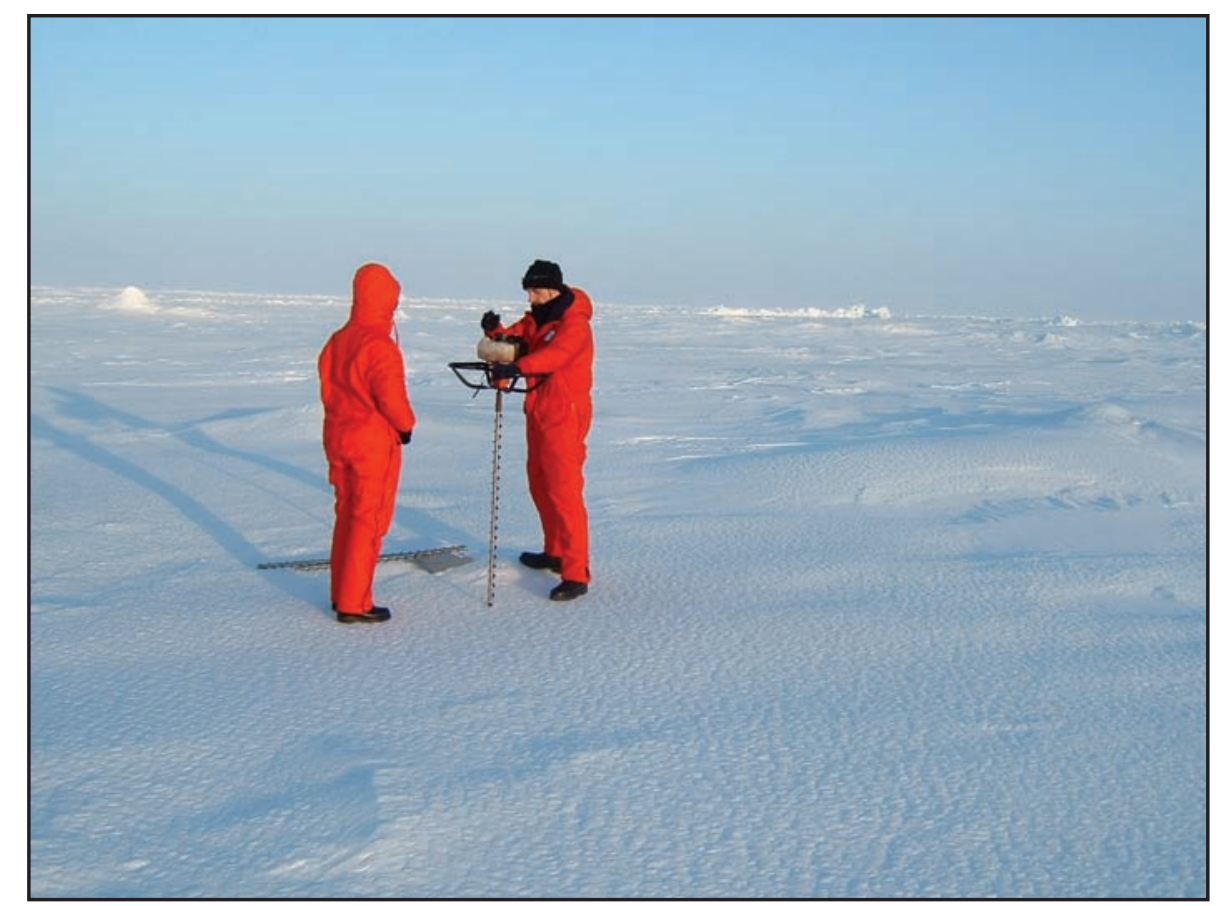

Isboring i Fram Strcedet. (Foto: Martin Doble)

vendes bl.a. af Dansk Rumcenter. Senest har amerikanerne med ICESAT opsendt et satellitbåret laseraltimeter, som også anvendes til istykkelsesbestemmelse. CryoSat ville være blevet det første satellitradaraltimeter, hvor havistykkelse indgår som en del af formålet. En radar opererer i modsætning til en laser uafhængigt af skydække.

Elektromagnetisk induktion: Måler induktion i isflagerne, opløsning afhænger af helikopterflyvehøjde, som skal være meget lav. Der eksperimenteres i dag med installation på lavtgående fly. Metoden er rimeligt sikker på regional skala.

Nagurny-metoden: lavfrekvent bølgeudbredelse i det Arktiske Ocean er relateret til istykkelsen. Metoden er udviklet teoretisk og kun delvist efterprøvet i praksis. Den giver et samlet havistykkelsesestimat for en stor del af det Arktiske Ocean.

\section{Alternativer}

Alternativt kan man kortlægge istyper med billeddannende mikrobølgeinstrumenter (SAR, scatterometer og radiometer) og dernæst opdele de forskellige typer i tykkelseskategorier. Selvom det ikke giver noget absolut mål for tykkelsen, giver det indblik i tykkelsesfordelingen.

En ikke uvæsentlig del af havismassen ligger i skruninger og deformationer. Tyndisområder er desuden vigtige for varmefluksen. Disse kategorier kan kortlægges med satellitbåren SAR, men er dårligt opløst med ULS og satellitbårne altimetre.

Europæisk havisforskning uden CryoSat Projektet GreenICE (2002-2005) er finansieret af EU, og formålet er at kortlægge specielt havistykkelse, udbredelse og udvikling nord for Grønland. Alle ovenfor nævnte målemetoder er blevet anvendt og afprøvet $\mathrm{i}$ forbindelse med projektet. GreenICE har deltagelse fra fire danske partnere nemlig DMI, DTU, DNRC og GEUS. Projektet slutter i år, men flere af aktiviteterne fortsættes i det kommende Internationale Polarår, IPY, (2007-2008) og i EU kommissionens bidrag til IPY, DAMOCLES (20052009). Disse projekter bidrager løbende til kortlægningen af klimaprocesser i og omkring havisen. Desværre kan man ikke uden CryoSat måle havistykkelsen uafhængigt af skydække og følge udviklingen af denne centrale parameter globalt, og det vil forsinke forståelsen af de processer, der har smeltet en del af den Arktiske havis.

\section{Ordforklaringer}

Altimeter: Nedadrettet radar på fly eller satellit, der måler afstanden til jordoverfladen ved at måle tiden for radarpulsen fra udsendelse til modtagelse.

CryoSat: Den første satellit i ESA's "Living Planet Programme" (www.esa.int/ livingplanet/cryosat) med forventet levetid på 3 år.

SAR: Synthetic Aperture Radar

ESA: European Space Agency

IPY: Det Internationale Polarår 2007-2008 DAMOCLES: Arktisk oceanografiprojekt 2005-2009 finansieret igennem EU's 6. rammeprogram, deltagelse af DMI, DTU, DNRC.

Termohalin: Temperaturen og saliniteten bestemmer massefylden og dermed i grove træk den vertikale bevægelse af havvand. 